\title{
Combined percutaneous balloon dilatation of the aortic valve and coronary angioplasty
}

\author{
N BISHOP, M R REES, A F MACKINTOSH \\ From Killingbeck Hospital, Leeds
}

SUMMARY A 75 year old man with severe angina caused by aortic stenosis and coronary artery disease was considered to be unsuitable for cardiac surgery after the recent removal of a bronchial carcinoma. Combined percutaneous balloon dilatation of the aortic valve and right coronary angioplasty considerably ameliorated the patient's angina.

\section{Case report}

A 75 year old man had a two year history of exertional angina and dyspnoea that was getting worse despite treatment with propranolol and bumetanide. Left heart catheterisation in May 1985 demonstrated an aortic valve gradient of $60 \mathrm{~mm} \mathrm{Hg}$. Coronary angiography showed a discrete $90 \%$ stenosis in the mid portion of the dominant right coronary artery (fig 1) and several areas of stenosis in the left anterior descending artery with a maximum narrowing of $90 \%$. On admission in November 1985 for aortic valve replacement and aortocoronary bypass surgery a preoperative chest $x$-ray demonstrated a mass in the upper lobe of the right lung. Cardiac surgery was cancelled and at lobectomy a well differentiated adenocarcinoma was removed; no local spread of tumour was found. No evidence of tumour recurrence was found in the following months but the angina became progressively worse, occurring when he walked across a warm room and at rest.

In September 1986 percutaneous coronary angioplasty and balloon dilatation of the aortic valve were attempted. The heavily calcified aortic valve was approached from the brachial artery and crossed with an exchange guide wire and progressively dilated with 10,14, and $16 \mathrm{~mm}$ balloons (Meditech). Each balloon was inflated three times for 20 seconds at a pressure of 3-5 atmospheres. The femoral artery pressure was recorded continuously and fell slightly during balloon inflation. The gradient was reduced to $35 \mathrm{~mm} \mathrm{Hg}$ (fig 2). Aortography demonstrated no

Requests for reprints to Dr A F Mackintosh, Killingbeck Hospital, York Road, Leeds LS146UQ. change in the minimal aortic regurgitation. A brachial guide catheter could not be positioned in the right coronary artery, so a femoral guide catheter was used. Narrowing of the right coronary artery was reduced from $90 \%$ to $30 \%$ with an ACS ultra-low profile $3.0 \mathrm{~mm}$ balloon. No attempt was made to dilate the diffusely diseased left coronary artery. The patient tolerated this 130 minute procedure and was discharged after three days.

One year later he has considerably improved effort tolerance. Apart from chest pain on walking up steep hills, he is free of angina.

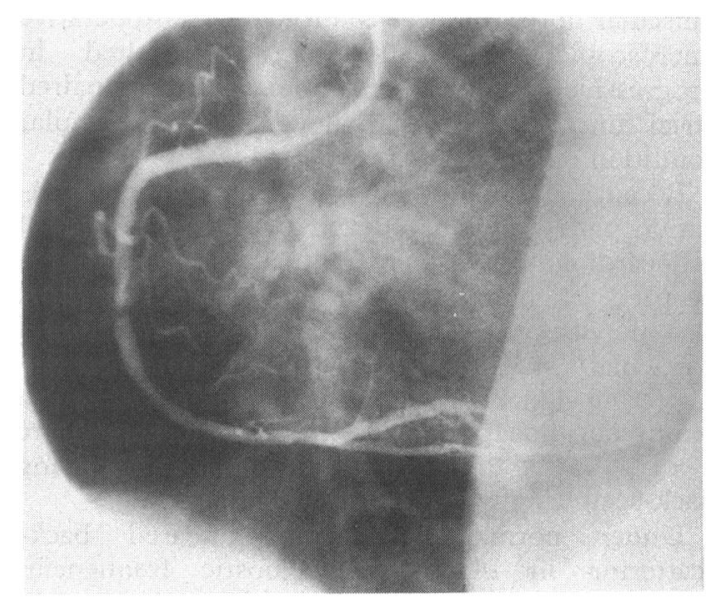

Fig 1 Right coronary angiogram before coronary angioplasty. 


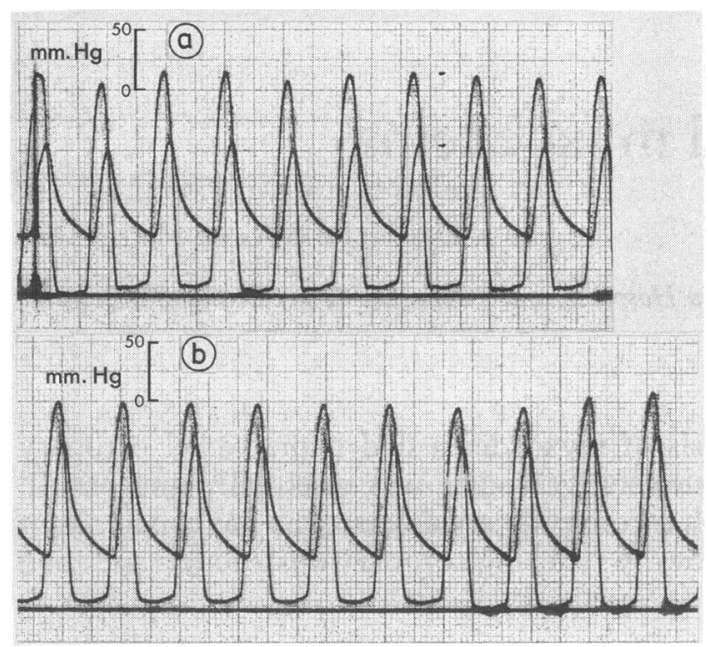

Fig 2 Simultaneous pressure traces from the left ventricle and femoral artery (a) before and (b) after aortic valvuloplasty.

\section{Discussion}

Angioplasty is a well established intervention that is suitable for some patients with coronary artery disease. Until recently many patients with severe aortic stenosis, for whom valve replacement was considered inappropriate, could be offered little effective treatment. Balloon dilatation of the calcified aortic valve has now been shown to be effective, though the safety and long term benefits of the procedure have yet to be established. ${ }^{12}$
Some patients with severe aortic stenosis and angina have clinically significant coronary artery disease. Our case shows that combined balloon dilatation of coronary stenosis and the aortic valve can produce worthwhile improvement in symptoms. Such palliative procedures may be appropriate in patients who are considered to be unsuitable for cardiopulmonary bypass surgery.

The duration of the combined procedure was prolonged because we could not obtain a stable position for the guide catheter in the right coronary artery from the brachial approach; but the patient remained comfortable throughout the procedure. The best sequence of balloon dilatations is uncertain. An initial coronary angioplasty would improve myocardial perfusion and might reduce the hazards of balloon dilatation of the aortic valve. ${ }^{3}$

\section{References}

1 Cribier A, Savin T, Saoudi N, Rocha P, Berland J, Letac B. Percutaneous transluminal valvuloplasty of acquired aortic stenosis in elderly patients: an alternative to valve replacement. Lancet 1986;i:63-7.

2 Jackson G, Thomas S, Monaghan M, Forsyth A, Jewitt D. Inoperable aortic stenosis in the elderly: benefit from percutaneous transluminal valvuloplasty. $\mathrm{Br}$ Med J 1987;294:83-6.

3 Starkey I R, Cumberland D C, Oakley G D G. Balloon aortic valvuloplasty for severe calcific aortic stenosis: effective but not without hazard [Abstract]. Br Heart $J$ 1987;57:69-70. 